\title{
IDENTIFICANDO NECESSIDADES DE CRIANÇAS COM DEFICIÊNCIA AUDITIVA: UMA CONTRIBUIÇÃO PARA PROFISSIONAIS DA SAÚDE E EDUCAÇÃOa
}

\author{
Identifying needs of children with hearing loss: a contribution to health and education \\ professionals \\ Identificación de las necesidades de los niños con discapacidad auditiva: una contribución \\ a los profesionales de la salud y la educación
}

\section{RESUMO}

Por tratar-se de condição crônica de graves consequências para criança, família e sociedade, a deficiência auditiva tem sido objeto de preocupação por parte dos profissionais de saúde. Este estudo objetivou identificar crianças em idade escolar, matriculadas no ensino fundamental da rede pública do município, conhecer o tipo de acompanhamento de saúde que recebem e identificar junto à família as necessidades que vivenciam em decorrência da deficiência auditiva. Utilizamos o Interacionismo Simbólico (IS) e a Narrativa como referenciais teórico e metodológico, respectivamente. Participaram da pesquisa seis famílias. As entrevistas foram gravadas e transcritas na íntegra. A família sente falta de suporte e infraestrutura do município para diagnóstico e reabilitação, além da falta de recursos e investimento no contexto escolar, sendo obrigada a se mobilizar para enfrentar essa situação. Esta pesquisa oferece subsídios para que ações de enfermagem e políticas públicas sejam pensadas para qualificar o cuidado à saúde desta população.

Palavras-chave: Perda auditiva. Criança. Enfermagem. Doença crônica.

\begin{abstract}
Hearing loss has been the subject of concern among health professionals, due to its chronic condition with severe consequences for children, families and society. This study aimed to identify school-age children enrolled in public elementary schools in the city, identifying the type of health assistance that they receive and identify the difficulties that the family experiences as a result of hearing impairment. It was used symbolic interactionism (SI) and Narrative as theoretical and methodological respectively. Six families participated in the survey. The interviews were taped and transcribed. The family misses the support and infrastructure of the municipality for the diagnosis and rehabilitation, in addition to lack of resources and investment in the school, being obliged to mobilize to confront this situation. This research provides background for thinking about nursing actions and public policies that may qualify the health care of this population.
\end{abstract}

Keywords: Hearing loss. Child. Nursing. Chronic disease

\section{Resumen}

La pérdida de audición ha sido objeto de preocupación entre los profesionales de salud, puesto que es una enfermedad crónica con graves consecuencias para los niños, las familias y la sociedad. Este estudio tuvo como objetivo identificar quienes son los niños en edad escolar matriculados en escuelas públicas de la ciudad, conocer el tipo de atención médica que reciben e identificar junto a las familias las dificultades que ellos viven a partir de la discapacidad auditiva de sus niños. Se utilizó la Interacción Simbólica (IS) y la Narrativa como referenciales teórico y metodológico respectivamente. Seis familias participaron de la encuesta. Las entrevistas fueron grabadas y transcritas. La familia siente la ausencia de apoyo e infraestructura del municipio para el diagnóstico y rehabilitación, además de la escasez de recursos e inversiones en la escuela, lo que les implica movilidad para enfrentar a esta situación. Esta investigación proporciona la base para pensar en acciones de enfermería y políticas públicas que puedan implementarse para la atención de la salud de esta población.

Palabras clave: Pérdida auditiva. Niño. Enfermería. Enfermedad crónica

\footnotetext{
'Enfermeira. Graduada pelo curso de Enfermagem da Universidade Federal de São Carlos (UFSCar) - São Carlos-SP. Brasil. E-mail: thais_scarpitta@hotmail.com; ${ }^{2}$ Enfermeira. Mestre em Enfermagem. Programa de Pós-Graduação em Enfermagem da Universidade Federal de São Carlos. Membro do Grupo Saúde e Família. São Carlos - SP. E-mail: sheilasvieira@yahoo.com.br; ${ }^{3}$ Enfermeira. Doutora. Professor Associado do Departamento de Enfermagem da Universidade Federal de São Carlos. Líder e pesquisadora do Grupo Saúde e Família/CNPq. São Carlos - SP. Brasil. E-mail: gdupas@ufscar.br
} 


\section{INTRODUÇÃO}

No mundo, a deficiência auditiva na infância apresenta uma prevalência de 1,5/1.000 nascidos vivos, com variação de 0,8 a 2/1.000. ${ }^{1}$ No Brasil, consoante ao Censo 2000 do Instituto Brasileiro de Geografia e Estatística (IBGE), existem 5.750.809 pessoas com deficiência auditiva, e destes 176.067 são incapazes de ouvir. A deficiência auditiva apresenta alta incidência e prevalência, e os custos com diagnóstico e tratamento são altos. ${ }^{2}$

A surdez infantil caracteriza-se por uma redução da audição em qualquer grau, que impede a criança de receber, perceber e reconhecer os sons normais em diferentes graus, podendo interferir no desenvolvimento da linguagem e da fala, o que acarreta dificuldades de aprendizagem e efeitos deletérios sobre a evolução social, emocional, cognitiva e acadêmica. $3,4,5$

A condição crônica é capaz de produzir diversas sequelas, entre elas: a limitação de funções e atividades, a dependência de aparelhos específicos e a necessidade de acompanhamento de saúde constante. Assim, a condição crônica é capaz de mudar a vida de todas as pessoas envolvidas no cotidiano da criança ${ }^{6}$, o que implica readaptações para enfrentar uma nova situação. ${ }^{7}$

Conviver com uma criança com deficiência auditiva pode despertar uma confusão de sentimentos na família, a qual cria expectativas e incertezas diante do diagnóstico da deficiência, que pode levar a uma desestruturação da dinâmica familiar. Isso mostra a importância de os profissionais de saúde oferecerem informações adequadas para a família enfrentar a nova situação. ${ }^{8}$

Revisando a literatura sobre deficiência auditiva, observamos que existem poucos estudos que mostram a experiência da família e criança com deficiência auditiva, sendo que a vida de ambas é afetada pela deficiência, como qualquer outra condição crônica.

Diante disso, esta pesquisa objetivou identificar crianças com deficiência auditiva, em idade escolar, matriculadas no ensino fundamental da rede pública de uma cidade do interior paulista para conhecer o tipo de acompanhamento de saúde que recebem e identificar junto à família as necessidades que vivenciam em decorrência da deficiência auditiva.

\section{MÉTODO}

A intenção em descobrir as dificuldades/ necessidades encontradas no cotidiano da família que convive com a deficiência auditiva nos fez optar pelo Interacionismo Simbólico $(\mathrm{IS})^{9}$ como referencial teórico, pois este possibilita compreender, através da experiência relatada pelo entrevistado, o significado que cada família atribui às situações enfrentadas no seu dia a dia e como reagem nos diferentes momentos da vida.
A Narrativa foi o referencial metodológico escolhido, um desenho de pesquisa que envolve narrativas individuais e a interpretação de seus significados. ${ }^{10}$ Busca compreender a experiência do sujeito investigado na sua própria perspectiva, cabendo ao pesquisador percebê-la e descrevê-la tal como é vivida e narrada pelas pessoas.

No momento em que a pessoa narra a história sobre sua vida e como é viver com a doença ou condição crônica, resgata-se o passado vivido antes da descoberta da deficiência e as novas situações enfrentadas após este marco, de modo que consiga reorganizar suas experiências de forma coerente e refletir sobre elas, dando um sentido a cada evento. Dessa forma, as informações obtidas através das entrevistas é uma forte estratégia para planejar o cuidado de enfermagem e como método de pesquisa em enfermagem. ${ }^{11}$

Este projeto foi aprovado pelo Comitê de Ética da Universidade Federal de São Carlos sob o parecer $n^{\circ} 449 / 2009$. Os sujeitos da pesquisa foram mães de crianças deficientes auditivas matriculadas no ensino fundamental das escolas públicas do Município sob estudo. 0 seu contato foi fornecido pela Secretaria da Educação do Município e no primeiro momento fizemos contato por telefone para explicar sobre a pesquisa e indagar sobre o desejo de participar dela. Mediante interesse, agendamos uma visita domiciliária, no momento e no local definidos de acordo com a disponibilidade da família, para início da coleta de dados após a assinatura do Termo de Consentimento Livre e Esclarecido (TCLE).

Para a coleta de dados, utilizamos a entrevista semiestruturada, tendo como questões norteadoras utilizadas ao longo dela: "Desde quando a criança tem problema auditivo?"; "Como é classificada a deficiência da criança (Tipo, Grau)?"; "Como tem sido o acompanhamento de saúde da criança?"; "Quais as necessidades e dificuldades encontradas no dia-a-dia devido a deficiência auditiva?". À medida que essas questões foram sendo resolvidas, outras frases foram formuladas no sentido de aprofundar o tema considerando os objetivos do estudo.

As entrevistas foram transcritas na íntegra, analisadas uma a uma, e posteriormente as narrativas comuns foram sendo agrupadas de modo a conferir a experiência narrada, uma sequência de fatos vivenciados pela família e pela criança com deficiência auditiva.

\section{RESULTADOS}

Foram identificadas, através da Secretaria da Educação do município, oito crianças com deficiência auditiva, sendo duas delas gêmeas e uma não localizada, o que nos remeteu a seis mães entrevistadas (Quadro 1). 
Quadro 1: Caracterização das crianças deficientes auditivas segundo idade atual, idade na ocasião da descoberta, ano escolar, causa, tipo e grau da deficiência.

\begin{tabular}{|c|c|c|c|c|c|c|}
\hline Criança & $\begin{array}{l}\text { Idade } \\
\text { atual }\end{array}$ & $\begin{array}{l}\text { Ano } \\
\text { escolar }\end{array}$ & $\begin{array}{l}\text { Idade por } \\
\text { ocasião da } \\
\text { descoberta }\end{array}$ & Causa & Tipo de deficiência & $\begin{array}{c}\text { Grau da } \\
\text { deficiência }\end{array}$ \\
\hline CDA1 & 7 anos & $2^{0}$ & 2 anos & Desconhecida & $\begin{array}{c}\text { Sensório-neural } \\
\text { bilateral }\end{array}$ & Severa \\
\hline $\mathrm{CDA} 2$ & 10 anos & $3^{0}$ & 1 a 2 meses & Meningite & $\begin{array}{c}\text { Sensório-neural } \\
\text { bilateral }\end{array}$ & $\begin{array}{l}\text { Severa e } \\
\text { Profunda }\end{array}$ \\
\hline CDA3a & 11 anos & $5^{0}$ & 1 ano & Prematuridade & $\begin{array}{c}\text { Sensónio-neural } \\
\text { bilateral }\end{array}$ & $\begin{array}{c}\text { Moderada e } \\
\text { Severa }\end{array}$ \\
\hline $\mathrm{CDA3b}$ & 11 anos & $5^{0}$ & 1 ano & Prematuridade & $\begin{array}{c}\text { Sensório-neural } \\
\text { bilateral }\end{array}$ & $\begin{array}{l}\text { Severa e } \\
\text { Profunda }\end{array}$ \\
\hline CDA4 & 10 anos & $5^{0}$ & 6 anos & Rubéola & $\begin{array}{l}\text { Sensónio-neural } \\
\text { unilateral direita }\end{array}$ & Severa \\
\hline CDA5 & 7 anos & $2^{0}$ & 4 anos & Desconhecida & $\begin{array}{c}\text { Sensónio-neural } \\
\text { bilateral }\end{array}$ & Moderada \\
\hline CDA6 & 8 anos & $1^{0}$ & 1 a 3 meses & Desconhecida & $\begin{array}{c}\text { Sensório-neural } \\
\text { bilateral }\end{array}$ & Profunda \\
\hline
\end{tabular}

A partir da análise das entrevistas construímos a narrativa sobre as necessidades e dificuldades vivenciadas pela criança e sua família em decorrência da deficiência auditiva, e o acompanhamento de saúde que vêm recebendo do município.

A história da criança com deficiência auditiva inicia-se quando a família percebe algo diferente na vida dessa criança. A família estranha a falta de comunicação no decorrer de seu crescimento, seja na deficiência da fala e/ou da audição ou ainda os professores desconfiam de algo errado no cotidiano escolar. Isso pode ser difíil para algumas famílias, as quais se negam a aceitar a possibilidade de uma deficiência ou acreditam ser algo esperado para a idade.

"Ele tinha dois anos, mas só que ele não falava nada, com dois anos e não falava nada." (Mãe1)

"A gente começou a notar que quando ele tava de costas, a gente chamava e ele não respondia de imediato, quando batia uma porta ou algum som forte que ele tava dormindo, ele não reagia." (Mãe2)

"Ela ficava mais no fundo da sala, começaram a perceber que ela não tava prestando atenção nas aulas, aí foi quando eu descobri que ela não tava ouvindo direito. [...] A minha mãe falava pra mim assim: "ela não escuta muito bem", eu falava: "Acha que ela não escuta! Ela escuta muito bem, criança né? Você fala e não presta atenção." [...] eu não desconfiei de nada, porque...ela começou a falar um pouquinho tarde, mas pra mim era normal." (Mãe4)
"Desde nenê eu falava com ela e ela não respondia [...] Foi quando ela começou a ir na escolinha e os professores começaram a falar que estava muito atrasada e que não estava normal. Eles falavam: "Ela não fala nada, nem fala o nome dela. [...] De pequena, era tudo mais alto, televisão, som, ela gostava de música bem alta. Só que às vezes a gente fala: "Ah, vai ver que não é isso né, porque tem hora que a gente não quer aceitar." (Mãe5)

"Esse problema a gente percebeu porque ela não se comunicava, chegou a idade de desenvolver a fala e ela não desenvolvia a fala. A gente começou a perceber ela um pouco absorta. A princípio, quando ela nasceu, ela tinha um pouco de audição e foi perdendo gradativamente com atrofiamento do nervo auditivo." (Mãe6)

Ao se dar conta do que está acontecendo, a primeira atitude da família é procurar ajuda médica, realizar exames a fim de investigar os problemas identificados. No entanto, a expectativa de esclarecer suas dúvidas muitas vezes não é alcançada, uma vez que o médico mantém a ideia de que 0 desenvolvimento da criança está normal, gerando uma demora no diagnóstico, que se confirma bem mais tarde. Assim, dependendo da conduta do médico, a família pode percorrer um longo caminho desde que percebe algo diferente na criança até o diagnóstico definitivo da deficiência auditiva, prejudicando ainda mais o desenvolvimento da criança pela demora em iniciar o tratamento.

"Aí a gente foi indo atrás e descobriu. [...] A gente desconfiou de bebê tal, ai foi pra Araraquara, e de lá 
que descobriram a deficiência com todos os exames que fizeram. [...] Demorou viu, porque os médicos falavam que era normal eles serem quietinhos, porque era pré-maturo, não sei o quê, aífoi descobrir já tinha quase uns três anos, que fez os exames, tudo." (Mãe3)

"Levei ela pra fazer exame de cabeça, pra ver se era alguma coisa na cabeça. Aí foi quando eu descobrique não era, era o ouvido. Aífizeram exame de ouvido e falaram que ela tinha uma perda em um dos ouvidos." (Mãe4)

"Eu decidi ir atrás pra ver o que era [...] Aí foi quando eu fui passar no Centro de Especialidades, e fiz duas audiometrias e o médico do Centro de Especialidades, falou: "Ah, eu não tenho certeza". Aífoi quando ele pediu o exame BERA, que ainda não tinha na rede pública, aí ele falou que tinha que esperar a Prefeitura liberar tudo. Ele falou que demorava um mês, um mês e pouco, aí liberou [...] Aí eu passava nos médicos e eles falavam que era normal, e que tem criança até 5 anos que demora pra falar. [...] Eeu passei em vários pediatras sabe, e eles falavam: "Não, essa menina vai falar, tem criança que demora." Aí eu fui esperando, esperando. [...] demorou mais de anos. Ela ficou esperando uns dois anos, dos 4 aos 6 anos de idade (pra conseguir o aparelho auditivo)." (Mãe5)

"A princípio nós levamos no pediatra, depois fomos encaminhados pra um otorrino, depois um especialista, aíforam feitos uns exames e se chegou a conclusão da deficiência auditiva irreversível [...] Foi detectada com um ano e três meses mais ou menos." (Mãe6)

Inicia-se então uma nova fase na vida da família que passa a conviver com a deficiência auditiva, sendo muitas vezes difícil enfrentar as mudanças diárias que a condição crônica ocasiona, sobretudo diante das dificuldades que a criança e a família encontram em sua vida, preocupação com a criança e por falta de informação sobre o que realmente está acontecendo com ela.

"Eu percebo que só o fato de ela ficar umas horas a mais do que outras crianças fora de casa, fazendo as atividades por causa da deficiência.... é assim: as crianças tem mais tempo do que ela pra brincar, mais tempo livre." (Mãe6)

"Esse médico do Centro de Especialidades não explicava muita coisa pra mim, aí quando eu leveio exame dela, a moça lá da Santa Casa que me explicou: "Olha, ela realmente não está ouvindo, vai ter que usar o aparelhinho, aí eles vão te encaminhar pra Bauru". Ela que me explicou [...] Aí o dia que eu fui levar o exame para o médico, pra ele dar os papéis pra mim ser encaminhada pra Bauru, ele só falou: "Ela não está ouvindo, vai ter que usar o aparelho", mas ele não explicou se era nas duas orelhas ou se não era." (Mãe5)

Em relação ao sistema de saúde, a principal queixa da família é a falta de suporte e infraestrutura do município para diagnóstico e reabilitação da deficiência. A assistência à criança com deficiência no município ainda está muito aquém do esperado e do necessário, pois são poucos os recursos oferecidos pelo município, poucos profissionais especializados, e nem todas as famílias conseguem tais benefícios de outros órgãos ou instituições públicas e também não tem recursos próprios para tal.

"A gente tem gastos com ele e não tem ajuda em nada [...] Uns tempos aí ele tava indo lá na Universidade, aí eu parei de levar ele por causa de passe, porque a gente não achou outra saída. [...] Por exemplo, amanhã a gente tem que gastar pra levar coisa pra comer lá em Bauru, tem que comprar marmitex lá. [...] Aqui na cidade (no município) só a assistente social que ele vai de terça-feira, que se chama "Criando Asas", mas eles não dão cesta (básica), não dão nada." (Mãe1)

"Então, aqui (no município) é assim, se você precisa de uma manutenção no aparelho, aqui você não tem, pelo SUS, pela prefeitura, nunca consegui. Se você precisa pilhas, também a gente que tem que comprar [...] É, tem essa parte de não ajudar muito no aparelho, que nem amanhã nós vamos pra Bauru, a gente vai sair daqui às sete horas da manhã e não tem hora pra voltar, então, quer dizer, é complicado, e se tivesse aqui não precisaria disso né. [...] $A$ primeira vez eu mandei consertar, pagamos do bolso, caro pra caramba." (Mãe2)

"Reclamo da saúde, porque quando você só tem uma criança que não tem nada, e quer só um pediatra, então pode falar bem da cidade, mas quando você tem outros problemas, não tem como falar bem, porque não tem recurso de nada, tudo não sabe de nada, você chega nos lugares e não consegue. Por exemplo, a fono, você não acha que nesta cidade deveria ter fono? Não tem! Acho que a rede pública tem uma fono... e quantas crianças tem?! [...] Nem a fono de graça eu consegui. Fico na fila, e 
quando chamou, acho que ano passado que eles ligaram aqui em casa, aí agora disse que aqui no posto tem, ela já ligou aqui em casa e falou se a gente tava interessado, eu falei que sim, mas até agora não chamaram, só se chamar hoje, porque não chamou ainda." (Mãe3)

"Os gastos são com as pilhas mesmo. [.. .] Desde quando eu ganhei o aparelho, sempre eu que comprei as pilhas. Só uma vez quando eu fui ver se ela estava se adaptando ao aparelho, que eles me deram as cartelinhas de pilha. Se não, eu que tenho que comprar mesmo." (Mãe5)

"Chegamos aqui, nós ficamos totalmente perdidos, porque nós percebemos que não havia interesse nenhum, nem por parte da prefeitura nem do governo federal, em relação ao deficiente. [...] 0 custo do aparelho é muito alto, não só na parte do aparelho em si, como a manutenção dele, e o mapeamento que tem que ser feito de seis em seis meses. [...] Tudo é pago por nós. Eu até me pergunto: "O que seria se nós não tivéssemos condições de pagar essas consultas?". Porque para as crianças com pais que não têm recursos, como que faz, não paga e não faz, né?" (Mãe6)

Diante da necessidade de suporte social evidenciada pelo depoimento das famílias, buscam-se alternativas para o acompanhamento da criança, destacando-se o apoio de amigos, a procura de serviços em outros municípios ou outros centros e profissionais da saúde, mesmo que tenha que lutar para obter transporte e verba para tratamento fora do município, onde conseguirão ser atendidas e receber a assistência que até o momento não tinham em seu município, principalmente aparelho auditivo e acompanhamento com profissionais de reabilitação.

"Veio uma moça aqui, de uma religião aí, e ela veio e falou pra mim que ia arrumar um aparelho pra ele. Aí ela marcou médico pra ele, levou ele no médico comigo, fez tudo os exames aqui, aí depois mandou pra Bauru, foi o médico da Vila Isabel que mandou pra Bauru. [...] Aqui não tem aparelho, depois passou pra Bauru e toda vez que tem que trocar o aparelho tem que ir lá. [...] aqui ele não faz nada, só em Bauru que lá tem tudo né. Tem psicólogo, assistente social, tudo ele passa um pouquinho." (Mãe1)

"Eu vou de carona com a Prefeitura daqui que manda. [...] 0 atendimento de lá (Bauru) é 100\% melhor do que o daqui, apesar de eu não ter nada contra, lá é muito melhor assim, porque lá você não passa só com o otorrino, você passa com otorrino, você passa com fono, com pediatra, com tudo, cardiologista, assistente social, com tudo, num dia só você passa com tudo [...] agora em Bauru, até pilha eles tão me dando." (Mãe2)

"Tem uma moça que cuidava mais ali (na escola), não sei se esse ano vai ser ela, foi ela que me ajudou a ir atrás do aparelho novo [...] Colocou aparelho lá (Araraquara), com 5 anos parece que ganhou o primeiro aparelho. Um tempão na fila esperando. [...] Uns três anos depois foi pra Bauru e lá conseguiu outro aparelho, que é o que ele tem hoje, que é bom, ele está novo. [...] demorou, todo mundo fala que demorou, mas corremos atrás do prejuízo né, as fonos e a gente, e hoje está fazendo tratamento em Bauru, que encaminhou pra lá e tal, agora está melhorando. [...] isso faz um ano mais ou menos. [...] Lá (Bauru) é muito bom. A gente chega lá, eles fazem todo tipo de exame no mesmo dia." (Mãe3)

"Quando ele diagnosticou, passou pra Ribeirão, colocou aparelho e voltou. [...] 0 doutor, que era médico do meu ex-cunhado, levou a proposta em Ribeirão, aí eu ganhei uma bolsa, aí eu paguei metade do aparelho [...] não demorou nem dois meses, foi coisa muito rápida, ele foi lá, já voltou, trouxe o aparelho" (Mãe4)

"Todos os exames agora ela faz em Bauru, e o aparelho eu também ganhei lá, então tudo eu tenho que passar lá. [...] Fiquei lá (Bauru) o dia inteiro, fez todos os exames lá, o que faz aqui tudo nesse tempo que demorou, lá faz em um dia. [...] Toda vez que precisa ir pra Bauru, a gente vai com a van. "(Mãe5)

\section{"Desde que nós chegamos, ela faz o acompanhamento com o pessoal da Federal, e duas vezes por semana ela faz Educação Especial. [...] O trabalho lá na Federal é com a fono." (Mãe6)}

No que diz respeito ao relacionamento da criança com a família, há dificuldades na comunicação. A demora no processo de aquisição da linguagem é uma dificuldade que a família encontra para educar a criança e compreender as suas necessidades, não sabendo como estabelecer uma comunicação adequada. Mesmo sabendo da importância da linguagem de sinais, a maioria opta por não utilizá-la e prefere estimular a oralização, a audição e a leitura orofacial. 
"Ah, era mais difícil viu. Agora que ele veio dar uma melhoradinha, mas antes não falava nada, a gente não sabia o que ele tava falando, pedia uma coisa e não sabia. [...] Agora não, a gente está mais acostumado. [...] Tem dificuldade ainda em entender e pra falar também" (Mãe1)

"Eram aqueles sinais básicos né - fazendo sinais com a mão - banho, comer, era assim, batia no ombro pra chamar a atenção dele. Ele fazia muitos gestos também. [...] Ele não pronunciava direito, e também, ele não pronunciava correto e nem entendia o que a gente falava. [...] Mas nós também já passamos por um período de adaptação difíiil no começo, que a gente não entendia o que ele falava, ele atropelava muito as palavras pra falar e era muito difícil a compreensão, tanto da gente com ele quanto dele com a gente. [...] Hoje ele faz libras também, faz libras uma vez por semana, só que quase não usa, pra ser sincera a gente quase não usa, porque a gente mais fala com ele." (Mãe2)

"A gente ficava falando as palavras, que eles apontavam [...] Eles lêem muito sua boca... se você fala rápido, ele manda você falar de novo, porque ele não entendeu. [...] Ele quer ler a sua boca, o lábio da gente. Aí tem que falar devagar pra ele entender o que quis dizer." (Mãe3)

"Ela vem aprendendo muito pouco de libras, porque a intenção dela como implantada, é que ela seja oralizada. Como ela já está sendo oralizada, a libras talvez venha a ser um suporte. Nós queremos que a comunicação, a linguagem principal dela, seja a oralizada. [...] Percebi que o ganho dela foi maior quando a gente começou a ter um contato mais oral do que gestual com ela. [...] Ela se comunica na maioria das vezes por leitura labial." (Mãe6)

Ao frequentar a escola, percebe-se que a deficiência auditiva traz importantes dificuldades para a criança em seu processo de alfabetização evidenciado por retardo na leitura, escrita e compreensão. De acordo com as famílias, essa situação está associada ao despreparo das escolas para lidar com crianças especiais e/ou à falta de atenção do aluno em sala de aula devido ao barulho, ou seja, a falta de recursos e investimento no contexto escolar influencia no desenvolvimento da criança.

"Ele tem dificuldade em tudo, em tudo. [...] Ele não presta atenção no que ele está fazendo, ele fica olhando pra um lado e pro outro. [...] Ele não sabe ler. Ele escreve o nome dele." (Mãe1)
"O acompanhamento dele na escola tem sido muito difícil, ele reprovou a segunda vez na terceira série. Ele está com dez anos e continua no terceiro ano, não tem acompanhamento nenhum na escola. [...] Na escola a dificuldade dele é porque ele não ouve o que a professora fala, mesmo com o aparelho, porque é muito barulho dentro da sala [...] (Dificuldade) na compreensão né, porque ele não ouve e ai não tem..." (Mãe2)

"Ah, acho que o problema é mais de escola, porque eles falam errado [...] Émais na sala de aula mesmo (a dificuldade) [...] Eles tem muita dificuldade na leitura. Se eu der esse papel ele vai ler, só que depois eu falo pra interpretar e aí não consegue [...] Na sala de aula é muito barulho, aí eles não escutam direito." [...] Então, a dificuldade mesmo é mais na leitura [...] eles são muito esforçados e querem aprender." (Mãe3)

"Ela ainda fala errado, mas a gente tenta corrigir sabe, eu e minha mãe, a gente corrige, mas o problema dela hoje é o aprendizado na escola, eu acho, porque ela escreve muito mal, então eu acho que o foco dela é ali. [...] Ela tem dificuldade na escrita. A professora falou pra mim que ela escreve muito mal. [...] A leitura dela está melhorando. Eu estou vendo que deu uma melhoradinha, mas também não é aquela coisa..." (Mãe4)

"Eu achei que pra ler, ela está lendo mais devagar, mas a professora falou que é assim mesmo, porque sempre tem uns que leem mais devagar. [...] Acho que tem coisas que ela compreende sim e outras não né, porque ela lê devagar e até entender..." (Mãe5)

"A dificuldade seria mais na compreensão do conteúdo que édado, que, pra mim, ézero. [...] Ela não lê nada. Isso que não entra na minha cabeça, nem ler ela sabe. Mesmo que ela não compreendesse ela deveria estar lendo, mas nem isso. [...] Ela não sabe ler. Ela sabe ler palavras soltas, tipo a, b, mas frases não. Nem palavras né, letras só. Palavras inteiras ela não sabe." (Mãe6)

As famílias notam o despreparo dos professores para lidar com crianças especiais e um desinteresse por parte deles pelo progresso da criança com deficiência em relação às demais, ou seja, há falta de recursos e investimento no contexto escolar. Sentindo-se preocupadas com o futuro de seus filhos, veem que se faz necessário buscar alternativas para suprir as necessidades da criança e melhorar o seu rendimento escolar. 
"No meio de tanta criança, (professores) não estão preparados, porque do jeito que ele é, no meio de tanta criança não ia adiantar muita coisa [... ] Então tem que ficar em cima dele. [...] Ele ia toda segundafeira (Educação Especial na Federal) e ficava lá estudando duas horas com uma professora sozinha. Ela ensinava ele." (Mãe1)

"Ela (professora) não tem uma atenção voltada, porque ele é o único aluno na sala com deficiência auditiva, e não tem uma atenção voltada pra ele na escola, na sala dele no caso [...] porque as professoras, em geral, não estão capacitadas pra atender uma criança com deficiência auditiva [...] Não tem uma pessoa capacitada pra dar uma aula pra ele." (Mãe2)

"Um dia eu até perguntei pra professora, eles nunca fizeram curso pra saber da deficiência de nenhuma criança. Elas não estão preparadas pras deficiências das crianças. [...] São 20, 30 alunos perfeitos e um deficiente. [...] Eu falei pra elas (professoras) que eles não são coitadinhos, do mesmo jeito que os outros tem a tarefa, tem que dar pra eles também né, pegar no pé. [...] Eu tive que colocar meus filhos na Educação Especial [...] É uma professora só pra eles. Agora vão ser duas horas. Ela senta com eles, vê toda a lição, ajuda no que eles não entenderam, ela dá atenção só pra eles, sem barulho em volta" (Mãe3)

"Olha, eu não sei se é a escola, se é por causa dos professores, porque eles não estão adaptados pra crianças igual ela. [...] A dificuldade que ela tem hoje é só na escola. Porque na escola ela vai muito mal, ela vai mal mesmo." (Mãe4)

"Eu percebo que não há preparo nenhum dos profissionais da escola. Isso desde o mais graduado até o menos graduado, não há preparação alguma, não sabem, nenhum professor, fora o educador especial que frequentava a escola, nenhum sabe libras. Não há classe especial, não há nenhum tipo de preparação por parte da escola. E eu também não vejo nenhuma preocupação por parte da escola, com o progresso ou a falta de progresso dela em relação à alfabetização. [...] Na parte da manhã, escola regular, e, na parte da tarde, a Educação Especial uma hora e meia." (Mãe6)

Com o tempo, a condição crônica da criança é incorporada à rotina familiar, permitindo a ela se adaptar às novas situações e superar aquele impacto inicial da descoberta.
É um reflexo de que a adesão ao tratamento está trazendo resultados positivos para a família e a criança. Ainda que em alguns casos seja complicado para a criança se adaptar ao aparelho auditivo/implante coclear, o uso destas tecnologias faz com que ela tenha audição mais acurada, o que provoca ganho nas relações familiares.

"Quando ele tava na rua, a gente chamava e ele não escutava. Aí com o aparelho, chama e ele escuta. Eassim, se eu peço: "pega tal coisa lá", ele pegava. Sem o aparelho não. [...] Ele não falava nada." (Mãe1)

"Então, no começo ele demorou um pouco pra se adaptar né com o aparelho, mas depois se adaptou normal." (Mãe2)

"Ah, eu acho que melhorou. Às vezes a gente falava e ela não escutava, mesmo assim, hoje com o aparelho, a gente chama, às vezes dá um grito, $e$ ela não escuta também. Não sei se ela faz que não escuta ou ela mesmo não escuta, tem mais essa também, mas eu acho que ela está bem. [...] Ela mesmo que põe e tira, depois que ela chega da escola ela tira, ela não fica sempre com ele, porque coça e com esse calor ainda piora e aí ela pega e tira." (Mãe4)

"Graças a Deus ela nunca reclamou de dor de cabeça, porque falavam que dava muita dor de cabeça, mas ela se adaptou bem. E ela gosta de usar, acho que é porque ela vê que está escutando agora. [...] Ainda bem que ela se adaptou bem. [...] Aí com o aparelho ela foi melhorando, melhorando. Melhorou bastante eu achei, ela está falando bem agora. Antes ela falava, mas tinha que conversar bem alto com ela." (Mãe5)

"Ela usou durante um ano, e como não houve ganho, e como ela se encaixava como paciente pra implante coclear, ai foi feito o implante. [...] No caso dela, como implantada, eu como mãe, elevando em conta o antes e depois, eu considero milagre o implante, um verdadeiro milagre pra quem é deficiente auditivo. [...] Hoje em dia, ela se comunica como uma criança que ainda está aprendendo a falar e ouvir, mas a comunicação dela de agora em relação há um tempo, pra mim, é praticamente 100\% [...] Eu fico muito contente pela melhora. [...] Ela manipula sozinha, ela sabe a função, ela sabe a necessidade desse aparelho, ela tem consciência que sem ele ela não ouve. Ela não gosta do aparelho, ela evita, pra ela talvez seja um pouco 
incômodo, porque não é uma sonoridade limpa como a nossa, fica metálica e robótica, então eu acho que incomoda um pouco." (Mãe6)

Aliado ao uso do aparelho auditivo/implante coclear, a família reconhece também a importância do acompanhamento com a fono ou ainda a ajuda de conhecidos para orientá-la quantos aos cuidados que podem ser prestados à criança direcionados ao desenvolvimento da linguagem (fala) e avaliar o processo de reabilitação da criança.

"Quando ele começou a fazer a fono, ela pediu que a gente parasse, pra pode motivar ele a falar, pronunciar e, quando ele falasse errado, a gente corrigir, não dar o que ele quiser enquanto ele não pronunciasse certo, e assim a gente foi fazendo, foi seguindo a risca tudo que ela falava, e aí ele foi melhorando bastante. [...] Muito do que a gente sabe hoje, do que a gente passa pra ele, foi a fono que passou pra gente, que até então a gente não tinha parado pra perceber. [...] Agora normal. [...] Nossa, ele melhorou muito, muito mesmo. [...] Uma vez por ano ele faz audiometria (no município) pra verificar se está perdendo mais ou não " (Mãe2)

"A fono étoda segunda feira, uma hora por semana. [...] Melhorou bastante na fala. [...] Agora eu só vou na fono de 6 em 6 meses, ela vê ele, mede ele, aumenta o volume se tiver baixo, troca o tubo... Ela que cuida do aparelho [...] ai troca tudo do aparelho, limpa o aparelho, ela aumenta; ontem eu levei e ela aumentou o volume do aparelho, porque achou que tava muito baixo" (Mãe4)

"Como eu não tinha orientação, eu comecei a passar com a professora da escolinha; ela falava: "Você tem que incentivar mais, vai falando mais alto." Às vezes eu trazia joguinhos, e ficava jogando com ela, aí ela também começou a me ajudar e ela começou a falar mais." (Mãe5)

"Eu vejo que o maior ganho vem da Federal mesmo (onde tem acompanhamento com fono). [...] Ela (fono) falou que não era mais pra pegar né, pra gente ir ensinando o que que era tudo, até hoje elas ensinam." (Mãe6)

É possível identificar que, apesar das dificuldades e mudanças que a deficiência acarreta, a família procura descartar a diferença da criança em relação as demais e manter sua vida o mais próximo do normal, oferecendo tudo aquilo que estiver ao seu alcance para que isto aconteça sem interferir no seu convívio social.
"Ele brinca normal como os outros [...] ele não gosta muito de assistir TV não. Ele gosta de ficar na rua brincando. A gente manda ele ficar aqui dentro, mas se distrai um pouquinho, ele já está na rua." (Mãe1)

"A gente tratava ele, sei lá, como um coitadinho, ai porque não pode isso, ai porque não vai fazer isso, e acabou sabe?! A gente trata ele normal. 0 que 0 outro pode fazer, ele também pode, porque ele é normal, ele só tem uma deficiência, mas ele é normal. [...] Hoje ele tem um contato normal, ele brinca normal, ele fala praticamente normal. Ele brinca, conversa" (Mãe2)

"A professora fala que eles têm um relacionamento muito bom, que não é de briga, nunca veio bilhete, essas coisas." (Mãe3)

"Ah, ela brinca normal, tem umas menininhas ali embaixo que de vez em quando de domingo à tarde eu deixo ela ir lá brincar, mas não é sempre, ela não sai muito de casa, mas ela brinca bem, ela se diverte bem, pelo menos com as meninas aqui de baixo ela brinca né. [...] em casa é normal, com as crianças ela brinca normal." (Mãe4)

"Em casa ela tem uma vida normal, eu acho. [...] As irmãs, eu tenho uma menina de 12 e outra de 9 , elas brincam com ela, ajudam. Ela tem um relacionamento bom com as irmãs. Tem uma coleguinha dela que vem brincar aqui em casa e que está na classe dela, aí as duas fazem lição juntas, ela brinca e interage bem."(Mãe5)

"Então seria como a maioria das crianças, vai em shopping, sai pra brincar na casa de primos, amigos. [...] Ela tem uma convivência na família assim, considerada bastante saudável. [...] Em relação ao comportamento dela, a vida social dela é como de qualquer outra criança. Ela brinca normal, ela é super sociável. [...] A disciplina que eu aplico a ela é a disciplina que eu aplico a qualquer outra criança. [...] Não tem nenhuma diferença, eu como já criei outro filho, eu vejo que não tem nenhuma diferença, nenhuma abertura assim: "ah, coitadinha, ela é deficiente [...] A deficiência nunca exigiu algo diferente dela, muito pelo contrário, ela é superpopular na escola, ela não tem problema nenhum de timidez, que era o meu medo, que ela tivesse um sentimento de inferioridade. Ela tem a consciência de que ela é diferente. Ela tem a consciência que ela sabe que não ouve." (Mãe6) 


\section{DISCUSSÃO DOS RESULTADOS}

A ligação e a interação da criança com os pais nos primeiros anos de vida, principalmente com as mães, facilita a identificação de qualquer alteração no seu desenvolvimento, o que explica em nossos achados o fato de a mãe desconfiar que algo não estava caminhando bem com a criança antes de obter o diagnóstico da deficiência auditiva. ${ }^{8,12}$ Ao perceber que a criança não ouve aos chamados e barulhos, a mãe decide investigar o que está acontecendo. Contudo, admitir ou aceitar que existe algo de errado com o filho não é tão simples, pois gera incertezas e dúvidas, sendo este um dos fatores que acaba repercutindo sobre a demora no diagnóstico precoce da surdez infantil, associado à não suspeita do pediatra em relação à surdez e ao fato de que nem todas as crianças apresentam uma deficiência auditiva profunda. ${ }^{5,15,12}$

Embora tenham se desenvolvido diferentes métodos de rastreio e de avaliações auditivas, há dificuldade em estabelecer o diagnóstico precoce da deficiência auditiva, ainda pouco frequente, confirmando a falta de suporte que encontramos em nossa pesquisa, muitas vezes pela reduzida participação das equipes de saúde no âmbito da prevenção primária, principalmente dos pediatras, na valorização e no encaminhamento para Triagem Auditiva Neonatal, a qual está sendo regulamentada pelo Projeto de Lei do Senado 504/2003 no país ${ }^{a}$. $>$ Se detectada tardiamente, a surdez infantil tem grandes repercussões no desenvolvimento da linguagem, já que a aquisição desta está diretamente ligada a audição, dificultando a comunicação com a criança, apontada no depoimento dessas mães e em outro estudo. ${ }^{5}$

Nossos relatos não trouxeram a maneira como 0 diagnóstico de surdez foi dado à família, porém exerce grande influência sobre os sentimentos da mãe, a qual vivencia um momento de incerteza, insegurança e medo diante do desconhecido, devido à falta de suporte e orientação. A partir desse momento, novas situações vão sendo apresentadas à família que passa a conviver com a doença crônica, se sentindo responsabilizada por direcionar seus planos e esforços em função da atual descoberta, buscando achar uma solução para o problema e poder ajudar a criança no seu processo de reabilitação, porque os pais almejam um desenvolvimento rápido da criança após o início do tratamento, seja com 0 aparelho auditivo ou a terapia fonoaudiológica, para que volte à normalidade e consiga superar o tempo perdido e as dificuldades impostas pela deficiência auditiva. ${ }^{8,12-15}$

Uma das dificuldades iniciais apresentadas pela mãe é a comunicação com a criança, e a literatura nos apresenta esse mesmo problema seguido de queixas relacionadas ao aparecimento de comportamentos agressivos e 0 isolamento social, revelando uma angústia na família por não conseguir compreender as necessidades do seu filho. ${ }^{14}$

Diante dessa circunstância e da falta de conhecimento sobre outra forma de comunicação que não seja a fala, a família procura acompanhar a criança em atividades recreativas com outras crianças e incentivar a oralização como forma de ela desenvolver habilidades de interação social, integrá-la ao mundo dos ouvintes e promover sua reabilitação, deixando em segundo plano a linguagem de sinais - LIBRAS. 3,8,16

A principal dificuldade da criança com deficiência auditiva está relacionada ao aprendizado escolar. Segundo as mães, a condição crônica não é o único motivo que explica essa dificuldade, principalmente de compreensão e escrita, analisando que os professores do ensino regular não estão preparados para receber o aluno surdo, atribuindo a ele uma posição de "coitadinho". ${ }^{6}$ Os professores não desenvolvem atividades direcionadas ao aprendizado da criança com necessidades especiais, ficando esta prejudicada quanto a escolaridade devido ao despreparo dos professores. ${ }^{18}$

Outros fatores apontados pelas mães estão associados a salas superlotadas e a ausência de uma equipe de suporte. No entanto, todos estes fatores não justificam as atitudes de exclusão dos alunos com qualquer tipo de deficiência que desejam aprender, podendo estes assegurar seus direitos à inclusão no ensino regular e educação através da língua de sinais. Além disso, a Lei de Diretrizes e Bases da Educação Brasileira (LDB, n 9394/1996) estabelece que os sistemas de ensino deverão assegurar professores especializados ou devidamente capacitados, que possam atuar com qualquer pessoa especial na sala de aula.

Pensando nisso, a escola regular ainda representa para muitos pais a possibilidade de inclusão social, o reconhecimento de suas potencialidades e o sonho de vê-lo se desenvolver como as demais crianças ouvintes, associado ao uso do aparelho de amplificação sonora individual (AASI), o qual é reconhecido com grande valor e benefício para as situações sociais de rotina diária de casa e no ambiente escolar, embora também desperte reações de frustração na família por tornar a criança diferente das demais, aumentando a desigualdade entre elas. 8,17

Assim, a família começa a lidar de forma mais tranquila e segura com a criança, manifestando um novo sentimento de aceitação e a consciência da deficiência. ${ }^{14,15}$

\section{CONSIDERAÇÕES FINAIS}

Embora algumas familias tenham se mostrado um pouco desesperadas ao se deparar com uma situação nova e não esperada para o seu filho, todas elas adotam a deficiência como um desafio e lutam a todo o momento para que a criança mantenha uma vida normal como as demais crianças de sua idade, buscando estratégias para superar as dificuldades no que diz respeito à falta de suporte social, saúde e educação.

Diante dessa situação, os profissionais de saúde, em geral, deveriam fornecer apoio para as famílias que tanto necessitam de suporte e esclarecimentos. Destacamos a importância do enfermeiro diante das ações de prevenção primária da deficiência auditiva, no que diz respeito à vacinação 
da gestante contra rubéola, controle da meningite, acompanhamento de otites de repetição e outras possíveis causas da deficiência auditiva. É importante também que o enfermeiro incentive a realização do "teste da orelhinha", acompanhe a criança nas consultas de puericultura e oriente a família sobre os sinais da deficiência auditiva, podendo assim ter grande influência sob o diagnóstico precoce de alguma anormalidade, evitando desta maneira uma intervenção tardia. Além disso, ajudar a família a enfrentar a confirmação do diagnóstico e as mudanças que possivelmente enfrentarão em sua vida em função à condição crônica é papel que o profissional precisa se preparar para desenvolver.

Foram poucos os estudos encontrados relacionados a suporte social oferecido à família e a criança com deficiência auditiva, sendo este extremamente importante para 0 enfrentamento de dificuldades, o que revela a necessidade de novas pesquisas que atrelem estudos sobre suporte social e deficiência auditiva.

Este estudo oferece um esboço inicial do panorama da deficiência auditiva que se quer desenhar do município, uma vez que o trabalho abarcou a rede municipal de ensino fundamental, tendo as mães das crianças como informante. Acreditamos ser necessário ampliar estudos que possibilitem ouvir a criança e a escola, assim como conhecer crianças matriculadas em escolas da rede estadual e particular que vivenciam esta experiência.

Apesar disso, acreditamos ter alcançado os objetivos propostos e que os resultados da pesquisa oferecem subsídios para que políticas públicas e ações de enfermagem possam ser pensadas para adequar o ensino regular, qualificar o cuidado à saúde e atender às expectativas desta população que vivencia uma situação crônica de saúde.

\section{REFERÊNCIAS}

1.Cecatto SB, Garcia RID, Costa KS, Abdo TRT, Rezende CEB, Rapaport PB, Análise das principais etiologias de deficiência auditiva em Escola Especial "AnneSullivan". Rev Bras Otorrinolaringol. [on-line]. 2003 mar/abr [citado 2010 dez 09]; 69(2):235-40. Disponível em: http://www.scielo.br/ $\mathrm{s}$ c i e l o.p p p ? p i d = S 00034 $72992003000200014 \&$ script $=$ sci_arttext $\&$ tIng $=e s$

2.Instituto Brasileiro de Geografia e Estatística-IBGE. Censo demográfico: resultados preliminares da amostra. Rio de Janeiro; [citado $2010 \mathrm{dez}$ 13 Disponível em: http://www.ibge.gov.br/home/presidencia/noticias/ 08052002tabulacao.shtm

3.Silva ABP, Pereira MCC, Zanolli ML. Mães ouvintes com filhos surdos: concepção de surdez e escolha da modalidade de linguagem. Psicol: Teor e Pesq. [on-line]. 2007 jul/set [citado 2010 dez 09]; 23(3): 279-86. Disponível em http://www.scielo.br/scielo
4.Vieira ABC, Macedo, LR de, Gonçalves DU. 0 diagnóstico da perda auditiva na infância. Pediatria. [periódico on-line] 2007 fev [citado 2010 dez 09]; 29(1): 43-49. Disponível em: http:// www.pediatriasaopaulo.usp.br/upload/pdf/1201.pdf

5.Gatto Cl, Tochetto TM. Deficiência auditiva infantil: implicações e soluções. CEFAC. [on-line] 2007 jan/mar [citado 2010 dez 09] 9(1): 110-15 Disponível em: http://www.scielo.br/

6.Silva MGN. Doenças crônicas na infância: conceito, prevalência e repercussões emocionais. Rev Pediatr. [on-line] 2001 maio/ago [citado 2010 dez 13] 2(2): 29-32. Disponível em: http://www.scielo.br/scielo

7.Vieira MA, Lima RAG de. Crianças e adolescentes com doença crônica: convivendo com mudanças. Rev. Latino-am Enfermagem. [on-line]. 2002 jul/ago [citado 2010 dez 13]; 10(4): 552-60. Disponível em: http://www.scielo.br/scielo.

8.Boscolo CC, Santos TMM. A deficiência auditiva e a família: sentimentos e expectativas de um grupo de pais de crianças com deficiência de audição. Distúrbios da comunicação [periódico on-line] 2005 abr [citado 2010 dez 13] 17(1): 6975. Disponível em: http://www.pucsp.br/revistadisturbios/ artigos/tipo_395.pdf

9.Charon JM. Symbolic interacionism: an introduction, an interpretation, an integration. $9^{\mathrm{a}}$ ed. New Jersey: Prentice Hall; 2007.

10.DriessnackM, Sousa VD, Mendes IAC. Revisão dos desenhos de pesquisa relevantes para enfermagem: parte 2: desenhos de pesquisa qualitativa. Rev Latino-am Enfermagem. [on-line] 2007 jul/ago [citado 2010 dez 13]; 15(4): 684-88. Disponível em: http://www.scielo.br/scielo.

11. Silva DGV, Trentini M. Narrativas como técnica de pesquisa em enfermagem. Rev. Latino-am Enfermagem. [on-line] 2002 maio/jun [citado 2010 dez 13]; 10(3): 423-32. Disponível em: http://www.scielo.br/scielo.

12.Silva ABP, Zanolli ML, Pereira MCC. Surdez: Relato de mães frente ao diagnóstico. Estud Psicol. [on-line]. 2008 ago [citado $2010 \mathrm{dez}$ 13]; 13(2): 175-83. Disponível em: http://www.scielo.br/scielo.

13.Almeida MI, Molina RCM, Vieira TMM, Higarashi IH, Marcon SS. 0 ser mãe de criança com doença crônica: realizando cuidados complexos. Esc Anna Nery. [periódico na Internet]. 2006 abr [citado 2010 dez 13] ; 10(1): 36-46. Disponível em: http://www.scielo.br/ scielo.

14.Oliveira RG, Simionato MAW, Negrelli ME, Marcon SS. A experiência de famílias no convivio com a criança surda. Acta Sci Health. [periódico on-line] 2004 jan/jun [citado 2010 dez 13]; 26(1): 183-91. Disponível em: http://periodicos.uem.br/ojs/index.php/ActaSciHealthSci/article/ view/1658/1072

15.Negrelli MED, Marcon SS. Família e criança surda. Ciênc Cuid Saúde. [periódico on-line] 2006 jan/br [citado 2010 dez 13]; 5(1): 98-107. Disponível em: http://periodicos.uem.br/ojs/index.php/CiencCuidSaude/ article/view/5146/3332 
16.Bergmann L. Repercussões da surdez na criança, nos pais e suas implicações no tratamento. Rev Espaço [periódico on-line] $2001 \mathrm{dez}$ [citado 2010 dez 13]; 16: 3-19. Disponível em: http://www.ines.gov.br/ paginas/revista/TEXT01.htm

17.Boscolo CC, Costa MPR, Domingos CMP, Perez FC. Avaliação dos benefícios proporcionados pelo AASI em crianças e jovens da faixa etária de 7 a 14 anos. Rev Bras Educ Espec [on-line] 2006 maio/ago [citado 2010 dez 13]; 12(2): 255-68. Disponível em: http://www.scielo.br/ $\mathrm{s}$ c i e l o . p h p ? p i d = S 14413 $65382006000200008 \&$ script=sci_arttext\&tlng $=$ en $\% 5$ D

18.Silva ABP, Pereira MCC. 0 aluno surdo na escola regular: imagem e ação do professor. Psicologia: teoria e pesquisa [on-line] 2003 maio/ ago [citado 2010 dez 13]; 19(2): 173-76. Disponível em: http:// www.scielo.br/scielo.

\section{NOTA}

aProjeto de Lei do Senado n ${ }^{0}$ 504, de 2003, que altera o art. 10 da Lei $n^{\circ}$ 8.069, de 13 de julho de 1990, que institui o Estatuto da Criança e do Adolescente, para tornar obrigatória a triagem auditiva neonatal em todo o País. 